\title{
Norma e formação: horizontes filosóficos para as práticas de avaliação no contexto da promoção da saúde
}

\author{
Norms and human development: philosophical \\ horizons for evaluation practices in the context \\ of health promotion
}

\footnotetext{
1 Departamento de Medicina Preventiva da Faculdade de Medicina, USP. Av. Dr. Arnaldo 455, 2o andar, 01246-903, São Paulo SP. jrcayres@usp.br
}

Abstract Health promotion has been widely described as a new and promising paradigm for health services. The emphasis in a comprehensive approach to care and prevention, the comittment to quality of life as a main goal and the assumption of community participation as a fundamental tool for services planning and monitoring are its main foundations. Despite the expressive production on health promotion, little have been discussed, however, on the necessary philosophical shifts this approach introduces in the way health practices are to be planned and evaluated. The objective of the present essay is to identify these changes and their consequences for health practices in general and evaluation procedures in particular. Philosophical Hermeneutics, Heidegger's ontology and Gadamer's approach to the Aristotelian concept of practical wisdom conform its interpretive framework. The main argument is that evaluation shall have its focus on the meaning of health practices for human development, beyond (and by means of) their technical objectives. Theoretical and practical implications of this philosophical perspective for evaluation procedures are also pointed out.

Key words Health promotion, Assessment, Health care, Philosophy
Resumo A promoção da saúde tem sido descrita como novo e promissor paradigma na saúde. Seus principais constituintes são a ênfase na integralidade do cuidado e prevenção, o compromisso com a qualidade de vida e a adoção da participação comunitária como peça fundamental do planejamento e avaliação dos serviços. Não obstante a expressiva produção sobre o assunto, pouco tem sido discutido, porém, sobre as inevitáveis transformações filosóficas que a proposta traz para o modo como as práticas de saúde devem ser planejadas e avaliadas. O objetivo do presente ensaio é identificar essas mudanças e suas conseqüencias para a organização das práticas de saúde, como um todo, e para os procedimentos de avaliação, em particular. A hermenêutica filosófica, a ontologia de Heidegger e a aproximação gadameriana ao conceito aristotélico de sabedoria prática conformam o quadro interpretativo utilizado. $O$ argumento central é de que a avaliação deve focarse no significado formativo das práticas de saúde, para além (e por meio) das suas finalidades técnicas. Procura-se também apontar alguns desdobramentos teóricos e práticos desta posição para os procedimentos de avaliação.

Palavras-clave Promoção da saúde, Avaliação, Cuidado, Filosofia 


\section{A promoção da saúde como desafio prático}

Entre as recentes propostas de reorientação das práticas de atenção à saúde destaca-se uma forte tendência à superação de modelos de atenção excessivamente centrados na doença, na assistência curativa, na intervenção medicamentosa, em favor de outros orientados ativamente em direção à saúde, isto é, às práticas preventivas, à educação em saúde e à busca da qualidade de vida, de um modo mais geral (Minayo et al., 2000). Esta tendência expressa-se, no seu pólo teórico, por proposições que vão desde a busca de construções conceituais nas quais a apreensão de agravos e riscos estejam intrinsecamente relacionados às condições mais gerais de vida $\mathrm{e}$ saúde, tais como as discussões em torno da vulnerabilidade (Mann \& Tarantola, 1996; Ayres et al., 2003), até ousadas proposições de uma conceituação positiva da saúde, isto é, um tratamento conceitual não negativo ou residual em relação à doença (Almeida Filho, 2001). No pólo da organização das práticas, esta ênfase na saúde tem sido construída em dimensões também diversas e inter-relacionadas, que vão de propostas de vigilância da saúde (Teixeira et al., 1998; Freitas, 2003) a proposições de promoção da saúde (Buss, 2000; Czeresnia, 1999).

A vigilância da saúde, ampliando escopo e métodos da tradicional vigilância epidemiológica, já realiza um deslocamento substantivo em relação a esta, quando vincula o controle de riscos e agravos a processos regionalizados e democratizados de definição de preocupações prioritárias e de estratégias de intervenção e monitoramento. Além disso, incorpora objetos de vigilância mais amplos que os agravos de notificação compulsória tradicionais, como questões nutricionais, saúde ambiental, saúde mental, relações entre saúde e trabalho, violência, entre outras. De outro lado, busca também acompanhar não apenas agravos e riscos, mas a própria adesão a cuidados de saúde, a adoção de medidas de autocuidado, a freqüência a consultas, a realização de screenings, etc.

As recentes propostas de promoção da saúde guardam estreitas afinidades com essa concepção ampliada de vigilância. Estão radicadas, em essência, na mesma compreensão do que seja a tarefa de assistir à saúde e, portanto, de seus objetos e estratégias. Contudo, ainda mais fortemente que na vigilância à saúde, aqui prevalece a concepção de que a saúde não se define apenas pelo monitoramento e controle do que a pode ameaçar. Uma definição negativa de saúde parece limitada sob a ótica da promoção. A ampliação que esta postula aspira intervir não apenas sobre o que se deve evitar para poder viver de forma saudável, mas quer também estabelecer patamares a serem alcançados, em termos de aquisições positivas para caracterizar uma boa qualidade de vida do ponto de vista físico, mental e social.

Uma vez em sintonia com essas proposições de reorientação, especialmente na perspectiva da promoção da saúde, uma série de desafios práticos inexoravelmente se colocam. Já desde um ponto de vista ético, moral e político surge a necessidade de se rever o excessivo apoio de instituições e culturas da saúde na racionalidade e autoridade científico-tecnológicas, o que, de resto, caracteriza as sociedades tardo-modernas de um modo geral (Habermas, 1987). Desta necessidade desdobram-se outras tantas, que são as que interessam mais de perto a este ensaio, e que dizem respeito ao paroxismo cientificista e tecnicista que domina as ações de atenção à saúde propriamente ditas (Gadamer, 1997).

As aspirações práticas da promoção da saúde, em seus intentos de democratização, pluralização, diversificação e singularização de meios e fins, apontam, evidentemente, para a superação de tradicionais paradigmas nos diversos campos disciplinares que informam a saúde pública. Veja-se, nesse sentido, o enorme desafio que consiste em produzir evidências epidemiológicas, estruturalmente vinculadas à construção e aplicação de conhecimentos nas práticas de saúde na atualidade, que incorporem variáveis de tão alta complexidade e tão substantivamente relacionadas a juízos e práticas moralmente vinculadas e vinculantes (Ayres, 2003). Mas se os desafios na esfera propriamente científica das ações de saúde já não são pequenos, o tipo de convite à mudança que parece se colocar aqui como irrecusável transcende o aspecto estritamente epistemológico, ainda que tenha implicações aí também. Trata-se de rever a própria situação do técnico e do científico em relação à orientação e legitimação das práticas de saúde.

Com efeito, a ultra-especialização e atomização analítica das disciplinas científicas da saúde, para além dos êxitos instrumentais alcançados, revelam limites quando se trata da organização das ações nos moldes da promoção da saúde, tal como acima descrita. Impõe-se, para isso, recorrer a dimensões racionalizadoras que 
superem a "dureza" das ciências e suas transcrições técnicas em arranjos tecnológicos mais capazes de integrar o poder instrumental daquelas a um sentido mais rico e eqüitativamente interativo de construção da saúde (Merhy, 2000). É necessário, em outros termos, que o aspecto técnico seja ativa e conseqüentemente posto em contacto com o não-técnico em cada momento assistencial. É necessário que se perceba que, para além do manuseio das regularidades de relações meios-fins, próprios às ciências e às técnicas, há em toda ação terapêutica, em qualquer escala que se as pense, um autêntico encontro entre sujeitos, no qual inalienáveis interesses de compreensão e simultânea construção do si mesmo e do outro estarão presentes. A depender do quanto se os considere e aceite no âmago das práticas de saúde, tais interesses estarão instruindo, com maior ou menor liberdade e efetividade, uma contínua e mútua reconstrução de identidades, concepções, valores e, portanto, projetos positivos de felicidade e saúde no (e a partir do) encontro terapêutico (Ayres, 2004).

A aceitação desta dimensão verdadeiramente "formativa" (Gadamer, 1996) do encontro terapêutico, isto é, da citada natureza compreensiva e construtiva do diálogo mediado pela técnica e pela ciência nas práticas de saúde, em quaisquer de suas aplicações e escalas, é que as fará ser designadas, deste ponto em diante, como "cuidado" (Ayres, 2004). E é no âmbito mesmo do cuidado, como prática fundamental para a promoção da saúde, que se quer colocar aqui em questão a avaliação em saúde. Entende-se que a avaliação constitui recurso técnico e político extremamente relevante para qualquer busca de reorientação da racionalidade das práticas de saúde, e a promoção da saúde não seria exceção.

Embora seja possível e útil distinguir entre objetivos mais particularmente científicos, tecno-administrativos ou político-gerenciais das práticas de avaliação (Novaes, 2000), ou ainda entre um caráter mais normativo ou causal-explicativo de seus desenhos e estratégias ( $\mathrm{Ne}$ mes, 2001), para efeitos da presente reflexão não serão discriminados esses diferentes escopos nem suas correspondentes variantes teóricas e metodológicas. Para as finalidades deste ensaio, basta a delimitação da avaliação, em sentido lato, como um conjunto de procedimentos sistemáticos que buscam dar visibilidade ao que é feito por referência ao que se pode e/ou se quer fazer com respeito ao interesse, efe- tividade, operacionalidade e qualidade de ações, tecnologias, serviços ou programas de saúde.

Isto posto, um primeiro aspecto da avaliação que precisa ser examinado quando se tem por norte a promoção da saúde refere-se à necessária revisão daquilo que se quer fazer nas práticas de atenção à saúde. Nesse sentido, a noção de cuidado poderá ser bastante iluminadora, pelo que permite ampliar o sentido dessas práticas para além do puramente instrumental.

\section{Êxito técnico e sucesso prático: pressupostos para avaliar o cuidado}

Ao se assumir a promoção da saúde como norte para a construção dos juízos que permitem formular o pressuposto "O que se quer e se pode fazer?" para avaliar uma determinada prática de saúde, uma primeira constatação é a de que não é suficiente adotar como critério normativo os padrões de correção de uma disfunção ou dismorfia, restabelecimento de um bem-estar físico ou psíquico ou prevenção e controle de uma certa ocorrência ou sua freqüência populacional. Ainda que este tipo de critério esteja longe de ser dispensável, ele se prende a uma dimensão instrumental, conforme apontado acima, que não esgota as finalidades do cuidado. A compreensão do sentido formativo das práticas de saúde, conforme discutido, implica expressivos enriquecimentos normativos, tanto em forma quanto em conteúdo.

Antes de mais nada é preciso ter claro que o sentido formativo remete a uma distinção filosófica fundamental entre os saberes de natureza científica e técnica (epistéme; techné) e o tipo de sabedoria que na filosofia aristotélica se denomina phrónesis, qual seja, uma racionalidade voltada à práxis. Práxis significa melhor realização da vida (energeia) do ser vivo, a quem corresponde uma "vida", uma forma de vida, uma vida que é levada a cabo de uma determinada maneira (bios) (Gadamer, 1983). No caso dos seres humanos, dotados de prohairesis, que significa capacidade de antecipação e escolha prévia, de escolher e negociar livremente, no contexto da polis, entre diferentes possibilidades de modos de vida, a práxis se refere, fundamentalmente, à ética e à política.

À busca sistemática desta sabedoria prática, Aristóteles denominou filosofia prática. Sobre 
esse tipo específico de saber, afirma Gadamer (1983): Certamente, a filosofia prática é também "ciência", isto é, um saber em geral que, enquanto tal, pode ser ensinado; é porém uma ciência sujeita a condições. Exige tanto da parte do que aprende, como da parte do que ensina, a mesma indissolúvel referência à práxis. Neste sentido, se encontra perto do saber especializado da techné. Porém, o que a separa fundamentalmente desta é que também se coloca a questão do bem - por exemplo, sobre a melhor forma de vida ou a melhor constituição politica - e não apenas, como o faz a techné, o dominio de uma habilidade cuja tarefa lhe está imposta por outra instância: pela finalidade que deve cumprir aquilo que se vai fabricar. Nesse sentido, a filosofia prática não é nem ciência teórica, ao estilo da matemática, nem conhecimento especializado, no sentido de dominio aprendido de processos de trabalho, quer dizer, "poiesis", mas uma ciência de um tipo particular. Ela mesma tem que surgir da práxis e se voltar novamente para a práxis (Idem).

Nos termos em que se vinha expondo a questão no presente ensaio, pode-se afirmar que, dado o caráter ético e político das práticas de saúde, a avaliação do cuidado não pode se deixar restringir à verificação de seu "êxito técnico", mas, entendendo esse êxito técnico como práxis, isto é, como simultaneamente exercício de escolha compartilhada de um modo de vida, deve estar também voltada para julgar acerca de seu "sucesso prático" (Ayres, 2001). Assim é que, ao se definir um horizonte normativo para as práticas de avaliação, há que se buscar junto das finalidades técnicas das práticas de saúde, mas transcendendo sua condição de estrita produção de objetos e objetividades (os produtos do trabalho em saúde), critérios relativos à antecipação, escolha e negociação de uma vida boa, ou, em outros termos, aos projetos de felicidade que justificam e elucidam a realização do cuidado que se quer julgar. Sob a égide desta recuperação da dignidade teórica de uma sabedoria prática, as questões que instruem as práticas avaliativas são reconstruídas: Como aparece ali, naquele encontro de sujeitos no e pelo ato de cuidar, os projetos de felicidade, de sucesso prático, de quem quer ser cuidado? Que papel temos desempenhado nós, os que queremos ser cuidadores, nas possibilidades de conceber essa felicidade, em termos de saúde? Que lugar podemos ocupar na construção desses projetos de felicidade que estamos ajudando a conceber? (Idem). Poder-se-á acrescentar aqui: Que significa orientar as práticas na direção da promoção da saúde? Que espécie de felicidade esse projeto visa alcançar? Como se redefine, nesse contexto, a participação de profissionais de saúde, gestores e formuladores de políticas, de um lado, e, de outro, usuários de serviços e populações-alvo das ações de saúde? Que espaços e meios de interação, conhecimento e intervenção são necessários para a construção dessas novas relações? Que implicações éticas e políticas podem ser vislumbradas nos processos de reconstrução tal como vêm se processando?

Há, contudo, uma especificidade na sabedoria prática, à qual Gadamer (1983) faz referência, e que impõe certos limites ao seu tratamento teórico, os quais não devem ser tomados como obstáculo, senão como desafios à sua ativa incorporação aos horizontes normativos da avaliação em saúde. Trata-se da estreita relação com a práxis que define mesmo qualquer sabedoria prática; esta sua estreita dependência do contexto de onde nasce e para o qual se volta imediatamente. Tal dependência tende a restringir o poder de generalização e a perenidade das relações que estabelece, visto deter-se sempre sobre situações e formas de comportamento mutáveis, a dirigir-se sempre a situações concretas. Esta condição é, de resto, muito avizinhada àquela vivida pelas ciências teoréticas chamadas ciências do espírito, ou ciências humanas, as quais têm raízes filosóficas compartilhadas com a tradição da filosofia prática (Gadamer, 1996). Não obstante, e de maneira análoga ao que acontece nas ciências humanas, o fato de que o saber originado da busca das melhores soluções nas diversas situações concretas tem em seu horizonte sempre a referência a um bem comum, a um modo de viver sempre compartilhado, e que precisa demonstrar-se bom por meio de procedimentos racionais sistemáticos, tudo isso determina a concepção de estruturas típicas que postulam validar-se em contextos diversos, que aspiram, nessa condição, o estatuto de um conhecimento da realidade.

As conseqüências que se pode extrair da condição acima descrita são de várias ordens, passando até mesmo pela importância para as práticas de avaliação das ciências humanas e seus processos de investigação e validação particulares. Para as finalidades deste ensaio, porém, interessa apenas destacar a impossibilidade de se estabelecer um conjunto de critérios $a$ priori para instruir práticas avaliativas que busquem superar o caráter tecno-normativo estri- 
to na direção formativa, tal como interessa à promoção da saúde. Esta perspectiva só autoriza, rigorosamente, que se apontem, ao modo não conclusivo de um convite filosófico, algumas possibilidades de inquirir as práticas de saúde a respeito de seus compromissos éticos e políticos com a construção dialógica da vida boa; de inquiri-las a respeito do lugar da saúde nos projetos de felicidade humana que se constroem cotidianamente com a participação (ou não) dos serviços de saúde.

Nesse sentido, uma hermenêutica do cuidado, desde as raízes ontológico-existenciais elucidadas por Heidegger (1995), na sua obra Ser e tempo, permitirá identificar alguns princípios capazes de expandir o horizonte normativo das práticas de avaliação, ainda que não caiba nos limites deste artigo explicitar seus fundamentos e procedimentos. Como se sabe, este filósofo desenvolveu a hipótese de que é a idéia de cuidado aquela que melhor nos permite compreender o sentido de nossa existência como humanos, estes seres que Aristóteles caracteriza como capazes de prohairesis. É o cuidado que revela, simultaneamente, o mundo em que se vive, isto é, o mundo que se antecipa, se escolhe e se negocia, e os sujeitos que o antecipam, escolhem e negociam. O cuidado é, portanto, o elemento hermenêutico que permite a autocompreensão e a (re)construção contínua e simultânea dos projetos humanos.

Segundo Heidegger, é na condição de um cuidar-se, um “tratar de ser” - que é, de um lado, um ato individual e individualizador, mas, de outro lado, também uma relação necessária com o outro, com um mundo compartilhado que forja a identidade de todos e cada um que se torna possível compreender a existência humana. Desde esse ponto de vista, o cuidar na área específica da saúde admite o mesmo tipo de leitura, especialmente se considerarmos o papel nuclear que as práticas de saúde adquiriram historicamente no processo formativo da civilização ocidental (Foucault, 2002). Identificar os constituintes histórico-ontológicos (não a priori) do modo de ser do cuidado constituirá um relevante recurso para sistematizar princípios orientadores de práticas avaliativas que, para além da eficácia tecno-normativa do controle dos agravos e riscos, possam ser sensíveis à positividade formativa dos projetos de saúde. Tais princípios não pretendem, obviamente, ser exaustivos, tampouco os mais relevantes, mas consistem num esforço de transpor para o campo particular da saúde algumas intuições e elaborações que se mostraram fecundas desde uma esfera de reflexão mais abstrata sobre a existência humana. São em número de nove os princípios deste modo identificados: movimento, interação, identidade/alteridade, plasticidade, projeto, desejo, temporalidade, não causalidade e responsabilidade (Ayres, 2004).

\section{O modo de ser do cuidado e os princípios para uma avaliação formativa}

Um primeiro traço característico do modo de ser do cuidado é o movimento. A construção de identidades humanas não é inscrita como um destino inexorável nas biografias dos sujeitos. Tais identidades vão sendo construídas no e pelo ato de viver, de colocar-se em movimento. $\mathrm{O}$ movimento será, de modo correlato, um elemento de extrema relevância para a avaliação formativa, em duas dimensões. Uma, mais bem explorada adiante, que diz respeito à própria situação da prática que se quer avaliar. Estar em movimento é condição sine qua non para que uma proposição prática qualquer realize seu propósito existencial. Mas para além dessa dimensão processual, a incorporação da necessidade mesma do movimento no âmbito interno de uma proposição prática para a saúde, como um estruturante dessa prática, é de igual relevância para julgar seu sentido construtivo. Estão os procedimentos técnicos ou gerenciais utilizados abertos ao movimento? Têm efetivamente estado em movimento? De que maneiras se abrem ao movimento? Que tipo de movimento pode ser observado? Eis algumas questões que podem ser feitas em processos avaliativos e que têm o potencial de produzir relevantes aportes às propostas de promoção da saúde.

A interação é um segundo traço fundamental do cuidado, pois o próprio pôr-se em movimento significa ir construindo uma série de relações. A possibilidade mesma de qualquer ser humano colocar-se em movimento em seus primeiros momentos de existência depende sempre da interação - com a mãe inicialmente, e com tantos outros direta e indiretamente nos momentos que se sucedem após o nascimento. Nesse sentido caberá argüir quanto às práticas avaliadas: Apercebem-se do seu caráter interativo? São atentas a essas interações? Favorecem a interação? Estimulam a interação? Que interações buscam estabelecer? Qual o sentido das interações produzidas? 
Há que se considerar, por outro lado, que as identidades dos diversos sujeitos em interação, nas práticas de saúde como na vida de modo geral, são produzidas exatamente no processo destas interações. Aqui de novo cabe a referência à criança que vai construindo sua identidade inicialmente através dos pais e a cada vez por processos mais complexos, e sempre em curso, de interações sociais. A contínua (re)construção de identidades e alteridades conformam, assim, um terceiro princípio a ser considerado. Tal reconstrução configura como que o conteúdo substantivo dos processos de interação intersubjetiva acima referidos. Por isso, caberá sempre perguntar nos processos de avaliação: Quem são os profissionais ou serviços e os usuários ou populações que se constituem mutuamente nos encontros efetivamente produzidos nas ações de saúde? Que qualidades os caracterizam? Que tipos de relação estabelecem entre si? Que significados possuem para eles esses encontros?

Tal tipo de questionamento faz, de fato, sentido para pensar as práticas de saúde devido ao quarto princípio a ser destacado: a plasticidade do cuidado, isto é, sua capacidade de transformar-se, mudar de formas, incorporar em si e nos seus objetos modos cambiáveis e cambiantes de manifestar-se. Assim como a criação de identidades-alteridades constitui o conteúdo substantivo das interações humanas, dos seus diferentes encontros, inclusive os terapêuticos, é a plasticidade que dota de sentido os movimentos e encontros do cuidar. Sem a plasticidade do cuidado o movimento das técnicas tenderia a zero, todas as relações entre meios e fins já estariam dadas a priori e de uma vez por todas. É na possibilidade de "(trans)formação" que se apóiam e se justificam os encontros criadores de identidades. É a plasticidade que dá sentido existencial a tais encontros. Cabe, então, perguntar-se: $\mathrm{O}$ quanto é plástico o arranjo tecnológico ou gerencial em questão? Quais são os pontos de maior plasticidade desse arranjo? Que implicações práticas podem ser relacionadas às características (de grau e de significado) da plasticidade própria a esse arranjo? Qual o significado dos movimentos observados ou antecipáveis nesse arranjo por referência aos seus significados formativos?

Porque essas antecipações são, como visto acima, constitutivas do modo de ser do humano, é que se pode definir o traço distintivo central de qualquer processo de cuidar como a concepção e realização (simultâneas) de um projeto existencial, seja no plano mais abstrato de uma ontologia, seja naquele mais concreto de um determinado arranjo tecnológico. Que modos de vida e de saúde são favorecidos com um determinado arranjo tecnológico ou gerencial das práticas de saúde? Que valores se colocam em relação com esse modo de vida, como sua origem e destino? Em que sentido é possível transformar os arranjos tecnológicos para que se construam os sucessos práticos vislumbrados em nossos projetos de vida e saúde?

O desejo, no sentido de pura expressão de uma livre vontade de existência, de um imponderável cogitar que faz emergir projetos de realização de ações ou alcance de estados conhecidos ou imaginados, é o sexto traço que se quer aqui destacar. O sentido construtor de autocompreensões e projetos de que se reveste o cuidado permite, com efeito, que este se defina também como um "encontro desejante com as circunstâncias", circunstâncias das quais se origina um modo de vida e às quais este visa sempre transformar. Talvez o desejo seja o princípio que maior dificuldade encontra para traduzir-se em orientações para práticas avaliativas, justamente porque por ele se quer designar o conteúdo mais inefável do modo de ser do humano, aquele que nos torna dotados da possibilidade de escolha e, por isso mesmo, nos faz tão indeterminados e misteriosos. Longe, porém, de fazer dessa dificuldade uma impossibilidade, a imponderabilidade do desejo só faz aumentar o interesse e a necessidade de que as práticas de saúde e, no seu âmbito, as práticas de avaliação, se submetam com freqüência e centralidade às perguntas mais relevantes e estruturantes para uma avaliação formativa: Qual o projeto de felicidade daqueles de quem se busca cuidar? Quais sucessos práticos se busca? Que êxitos técnicos podem colaborar para esses sucessos? Como podem fazê-lo?

Temporalidade é o sétimo princípio. A perspectiva temporal do cuidado é um desdobramento lógico do modo de ser do cuidado tal como aqui defendido, já que a idéia central de projeto só faz sentido numa perspectiva temporalmente definida, em que a experiência da consciência se parte em uma dimensão pretérita, fonte dos juízos fundamentados acerca do ser do mundo e de si mesmo, uma dimensão futura, em direção ao qual se antecipam possibilidades e perseguem estados desejados, e uma experiência atual que estrutura e relaciona tais juízos e desejos. A temporalidade tem implicações diretas, portanto, em qualquer processo de 
avaliação, já que esse aspecto será decisivo para que se possa qualificar e mensurar qualquer arranjo tecnológico, seja na perspectiva normativa do êxito técnico, seja naquela formativa, referente aos sucessos práticos. Qualquer resultado que se esteja obtendo hoje de uma determinada prática de saúde só poderá ser julgado quanto ao atendimento de uma certa finalidade instrumental se for considerado quando e quanto, a cada momento, se exige dela como padrão esperado de rendimento e resposta. Por outro lado, desde uma perspectiva formativa, será preciso sempre relacionar temporalmente experiências prévias, situação atual e potencialidades para julgar quanto à pertinência, legitimidade e adequação do cuidado que se está oferecendo: Quais os fundamentos práticos (práxicos) de um determinado arranjo tecnológico? Em que experiências históricas se funda? Que sujeitos históricos têm participado de sua construção? Quais são as bases éticas, políticas, epistemológicas e lingüísticas em que se apóiam? Que perspectivas de futuro permitem vislumbrar em seu desenvolvimento?

Delicadas e aparentemente estranhas estas dialéticas, nas quais os princípios se implicam mutuamente - o tempo sendo condição do projeto, e o projeto sendo o conteúdo que especifica o que é presente, passado e futuro; o desejo construindo a história, sem a qual, por sua vez, não existe desejo; o projeto como fundamento do cuidado, ao mesmo tempo em que o cuidado é a condição de possibilidade do projeto. Toda essa complexa rede de mútuas implicações conduz ao oitavo princípio a ser destacado: o da não-causalidade, isto é, da irredutibilidade dos processos formativos do humano a uma apreensão cognitiva do tipo causa-efeito. Como se sabe, esse modo de apreender relações de determinação caracteriza-se por uma sucessão linear de eventos no tempo e no espaço, uma independência formal entre causa e efeito e uma direção unívoca da causação absolutamente estranhas ao tipo de determinação que relaciona o cuidado aos seus constituintes aqui identificados. Este princípio aponta claramente os limites da metodologia científica oriunda das ciências exatas e experimentais e sua tradicional fundamentação lógico-matemática para os propósitos de uma avaliação formativa. Ainda que se possa, e freqüentemente se deva, incorporar raciocínios causais e deduções lógico-matemáticas a processos avaliativos, posto que relações meiosfins são indissociáveis das técnicas e estas são o substrato do que se quer avaliar, quando o propósito da avaliação se orienta para uma perspectiva formativa é necessário que seus componentes cognitivos sejam sempre regidos por uma aproximação hermenêutica. Isto é, qualquer proposição avaliativa deve fazer parte de um círculo compreensivo, no qual cada parte em exame só tem seu significado esclarecido por uma totalidade interpretativa, a qual deverá ter seu significado completamente dependente de cada uma das partes examinadas. Nesse sentido, não se pode conceber que uma avaliação formativa possa considerar os processos e resultados de qualquer componente técnico isolado do sentido que lhe imprime seu pertencimento ao arranjo tecnológico mais amplo onde está inserido. Delimitar quais são as totalidades interpretativas necessárias à elucidação de sentido do conjunto de práticas em questão, assim como definir o meio mais econômico e eficaz de operá-la na prática avaliativa, constituem, portanto, um dos mais instigantes e necessários desafios metodológicos de uma avaliação formativa. Dito de outra forma, defendese que, no âmbito de uma avaliação formativa, cada pergunta sobre relação causa-efeito deve ser sempre circunstanciada, contextualizada, nunca absolutizada ou naturalizada, ao mesmo tempo que outros questionamentos de moldes não-causalistas não podem deixar de ser feitos, do tipo: de que modo valores, princípios e práticas estão se reconstruindo mutuamente no processo de desenvolvimento das ações sob avaliação?

Se o cuidado só se deixa apreender por essa circularidade hermenêutica, o arranjo das relações parte-todo que o caracterizam será sempre um ato arbitrário de quem se ocupa dele, isto é, de um sujeito avaliador que, como tal, "cuida do cuidado". Não há um ponto de entrada necessário por qualquer das partes constitutivas de sua totalidade interpretativa. Por isso mesmo, não há também uma definição $a$ priori da totalidade que responde pelo modo de ser do cuidado, da mesma forma que o próprio cuidado é, como apontado acima, um projeto mutuamente determinado e determinante de escolhas e contingências. Portanto, tanto no modo de ser do cuidado, como no modo de ser de sua avaliação formativa, a responsabilidade constitui um princípio fundamental. Pela situação histórico-ontológica do humano, tanto mais quanto se aperceba e aproprie dela, é a possibilidade e a necessidade de responder pela autocompreensão e construção formativa do 
nosso modo de ser no mundo que nos torna, a cada um de nós e a cada conjunto de nós, responsável pelas implicações práticas (práxicas) do cuidado - nos seus momentos de execução tanto como nos de avaliação. Este nono princípio sugere, portanto, formas e conteúdos de questões para avaliação que privilegiam o circunstanciamento e a explicitação de perspectivas interpretativas. Apóiam-na no pressuposto epistemológico de uma estreita relação entre o técnico o ético e o político, imediatamente envolvidos em qualquer desenho de avaliação que leve a sério a dimensão formativa. Nesse sentido, serão perguntas inexoráveis e, talvez mesmo, as primeiras que devem ser feitas: Quem responde pelo cuidado em questão? A que responde? A quem e o que deveria responder? O mesmo tipo de questionamento cabe ao processo avaliativo.

\section{Promoção da saúde e avaliação formativa, à guisa de conclusão}

Com a trajetória reflexiva aqui desenvolvida, pensa-se ter fundamentado de forma minimamente consistente a tese, afirmada logo ao início do texto, de que os novos horizontes abertos pelas propostas de promoção da saúde, em sentido lato, reclamam e requerem, para seu pleno sucesso, uma prática avaliativa decidida e conseqüentemente comprometida com a identificação e participação na construção de projetos de felicidade humana.

Nesse sentido, para além e junto do monitorar do êxito técnico, instrumental, dos arranjos tecnológicos e gerenciais das práticas de saúde, é preciso que a avaliação elucide e favoreça as potencialidades das práticas de saúde para gerar processos criativos e solidários de melhoria da vida de indivíduos, comunidade e populações. Ou seja, participando como um dispositivo de autocompreensão e construção das necessidades e aspirações humanas, as práticas avaliativas devem poder orientar-se continuamente para a obtenção de sucessos práticos.

A uma avaliação em saúde que se compreende nesta perspectiva autocompreensiva e sócio-historicamente (re)construtiva, passou-se a chamar, por inspiração da tradição da filosofia prática que suporta e justifica tal identidade, avaliação formativa, num necessário contraste (mas nunca oposição) com as chamadas avaliações normativas.

A hermenêutica do cuidado permitiu, por fim, delimitar, ao modo de um convite, uma série de princípios potencialmente instrutores de avaliações formativas, seja no que se refere à sua atitude ética e política, aos seus pressupostos epistemológicos e metodológicos, ou aos seus conteúdos específicos.

Tem-se aqui a clara consciência de duas limitações não desprezíveis do presente ensaio, entre outras, não tão relevantes ou perceptíveis. A primeira delas diz respeito ao seu relativamente alto grau de abstração e, de modo proporcional, às complexas mediações filosóficas envolvidas. Dois tipos de conseqüências, igualmente indesejáveis, podem advir dessa limitação. Uma delas se refere às insuficiências do autor para transitar por tão delicadas mediações conceituais. Quanto a esta, só cabe advertir o leitor para uma redobrada vigilância crítica. Mas outra conseqüência importante, e que se deve tratar com mais vagar, é a possibilidade de que a complexidade das questões aqui levantadas paralisem o leitor, seu potencial beneficiário.

Com efeito, um mergulho tão radical nos horizontes filosóficos da avaliação podem ter deixado o contexto da promoção da saúde muito distante. Conduzir os princípios propostos para uma avaliação formativa até os limiares de práticas concretas de avaliação pode mostrar-se uma tarefa de grande dificuldade. Não se desconhece aqui este tipo de dificuldade, até porque o autor, em sua prática de sanitarista, as experimenta cotidianamente. Não obstante, faz parte também da experiência do autor (e não apenas dele, naturalmente) a convicção de que investimentos na fundamentação filosófica, ainda que num primeiro momento imponham dificuldades práticas de mediação conceitual, revertem em possibilidades renovadas e ampliadas de um manuseio e diálogo mais coerente e consistente por referência às práticas visadas. Para esse tipo de dificuldade, recomenda-se a mesma atitude que se pode adotar diante das inúmeras outras dificuldades que cercam a efetivação das práticas de avaliação - como a falta de tempo, de recurso, de formação ou de uma cultura institucional favorável. Trata-se da adoção de critérios de realismo, fecundidade e operacionalidade na escolha de que, como e quando avaliar (Ayres, 1996).

Uma segunda ordem de limitações deriva do restrito diálogo estabelecido com a produção teórico-filosófica do campo específico da avaliação. Tal restrição não deve ser entendida como desconhecimento ou descaso em relação à expressiva produção desta área, especialmen- 
te na América do Norte. Trata-se apenas do fato de que o autor não é um estudioso do assunto e o que buscou nesse ensaio foi, justamente, lançar pontes entre uma reflexão filosófica mais abstrata, voltada para a compreensão das práticas de saúde de modo geral, e as questões que se vêm apresentando como campos relativamente diversos de indagação, mas estreitamente inter-relacionados, quais sejam aqueles que vêm se debruçando sobre as práticas avaliativas e os que vêm procurando desenvolver conceitual e tecnicamente as proposições da promoção da saúde. Aliás, também em relação a estas últimas não seriam menos pertinentes eventuais críticas à estreita base de interlocução teórica. Julga-se, porém, que só um esforço decidido de construir pontes interdisciplinares e transregionais no campo da produção teórica, assumindo-se todos os riscos de eventuais insuficiências e imprecisões inerentes a em- preitadas desse tipo, pode fazer caminhar o conhecimento de forma transdisciplinar e enraizada em desafios práticos abrangentes, de solução necessariamente plural e coletiva.

Uma última consideração diz respeito à dificuldade prática e à verdadeira "aposta" que significa, para especialistas em avaliação ou técnicos e gestores avaliadores de seus próprios trabalhos, a incorporação da perspectiva aqui chamada formativa em seus processos avaliativos cotidianos. A maior visibilidade e familiaridade com a aplicação da metodologia científica tradicional para monitorar processos e resultados do trabalho em saúde tende a tornar quase automática a adesão restrita às perspectivas normativas da avaliação. A reflexão acima aponta, contudo, a necessidade de mais ativa adesão à avaliação formativa quando se trata de reconstruir as práticas de saúde na direção da promoção da saúde.

\section{Referências bibliográficas}

Almeida Filho N 2001. For a general theory of health: preliminary anthropological and epistemological notes. Cadernos de Saúde Pública 17(4):753-770.

Ayres JRCM 1996. Educação preventiva e vulnerabilidade às DST/AIDS e abuso de drogas entre escolares: Como avaliar a intervenção?, pp. 25-4. In DA Tozzi et al.(orgs.) Papel da educação na ação preventiva ao abuso de drogas e às DST/AIDS. Fundação para o Desenvolvimento da Educação, São Paulo (Série Idéias, No. 29).

Ayres JRCM 2001. Sujeito, intersubjetividade e práticas de saúde. Ciência e Saúde Coletiva 6(1):63-72.

Ayres JRCM 2003. Epidemiologia, promoção da saúde e o paradoxo do risco. Revista Brasileira de Epidemiologia 5(Supl.1):28-42.

Ayres JRCM 2004. Cuidado e reconstrução das práticas de saúde. Interface - Comunicação, Saúde, Educação 8(14):73-91.

Ayres JRCM, França Júnior I, Calazans GJ \& Saletti Filho HC 2003. O conceito de vulnerabilidade e as práticas de saúde pública: perspectivas e desafios, pp. 117-139. In D Czeresnia \& CM Freitas (orgs.). Promoção da saúde: conceitos, reflexões, tendências. Ed. Fiocruz, Rio de Janeiro. 
Buss PM 2000. Promoção da saúde e qualidade de vida. Ciência e Saúde Coletiva 5(1):163-177.

Czeresnia D 1999. The concept of health and the difference between prevention and promotion. Cadernos de Saúde Pública 15(4):701-709.

Foucault M 2002. História da sexualidade III: o cuidado de si. Edições Graal, Rio de Janeiro, 246 pp.

Freitas CM 2003. A vigilância da saúde para a promoção da saúde, pp.141-159. In D Czeresnia \& CM Freitas (orgs.) Promoção da saúde: conceitos, reflexões, tendências. Fiocruz, Rio de Janeiro.

Gadamer HG 1983. Hermenêutica como filosofia prática, pp. 57-77. In HG Gadamer. A razão na época da ciência. Ed. Tempo Brasileiro, Rio de Janeiro.

Gadamer HG 1996. Verdad y método: fundamentos de una hermenéutica filosófica I. Ed. Sígueme, Salamanca.

Gadamer HG 1997. Teoria, técnica, prática, pp. 11-37. In HG Gadamer, O mistério da saúde: o cuidado da saúde e a arte da medicina. Edições 70, Lisboa.

Habermas J 1987. Técnica e ciência como ideologia, pp. 45-92. In J Habermas. Técnica e ciência como ideologia. Edições 70, Lisboa.
Heidegger M 1995. Ser e tempo I. Ed. Vozes, Petrópolis.

Mann JM \& Tarantola DJM 1996. From epidemiology to vulnerability to human rights, pp. 427-476. In JM Mann \& DJM Tarantola (eds.). Aids in the world II. Oxford University Press, Nova York.

Merhy EE 2000. Um ensaio sobre o médico e suas valises tecnológicas: contribuições para compreender as reestruturações produtivas do setor saúde. Interface Comunicação, Saúde, Educação 4(6):109-116.

Minayo MCS, Hartz ZMA, Buss PM 2000. Qualidade de vida e saúde: um debate necessário. Ciência er Saúde Coletiva 5(1):7-18.

Nemes MIB 2001. Avaliação em saúde: questões para os programas de DST/AIDS no Brasil. Associação Brasileira Interdisciplinar de Aids, Rio de Janeiro.

Novaes HMD 2000. Avaliação de programas, serviços e tecnologias em saúde. Revista de Saúde Pública 34(5):547-559.

Teixeira CF, Paim JS \& Vilasbôas AL 1998. SUS, modelos assistenciais e vigilância da saúde. Informe Epidemiológico do SUS VII(2):7-28.

Artigo apresentado em 26/4/2004

Aprovado em 4/6/2004

Versão final apresentada em 24/6/2004 